\title{
全面二孩政策对中国人口结构及区域 人口空间格局的影响
}

\author{
王开泳 ${ }^{1,2}$, 丁 俊 ${ }^{1,2,3}$, 王甫园 ${ }^{1,2,3}$ \\ (1. 中国科学院地理科学与资源研究所, 北京 $100101 ; 2$. 中国科学院区域可持续发展分析与 \\ 模拟重点实验室, 北京 $100101 ; 3$. 中国科学院大学, 北京 100049)
}

\begin{abstract}
摘 要: 从“单独二孩”到“全面二孩”, 近几年中国生育政策的连续调整, 不仅引起了社会的强烈反响, 而且也将对中 国未来的人口结构和空间格局产生重要影响。本文利用人口学的队列元素法对全面放开二孩政策实施后, 中国未 来总人口及人口结构的变化趋势进行预测, 并从地理学的角度分析了全面放开二孩对中国区域人口空间格局的影 响。结果表明: (1)全面放开二孩可以有效延缓中国总人口的递减趋势、老龄化的趋势以及未来劳动人口不断走低 的趋势; 2)全面放开二孩政策前后, 中国的区域人口空间分布均呈现东部人口密度最高、中部次之、东北再次、西部 最低的总体格局, 全面放开二孩将会增加胡焕庸线东南侧的人口密度, 中国人口分布东南集聚、西北相对稀疏的格 局将会长期存在并进一步加剧; 3根据各省全面放开二孩政策后未来 15 年人口变化强度, 可划分为人口快速变化 区、人口中速变化区、人口缓慢变化区和人口平稳区。
\end{abstract}

关 键 词: 全面二孩政策; 人口结构;空间格局; 影响; 中国

\section{1 引言}

自 20 世纪 70 年代起, 为了控制人口过快增长, 中国实施了计划生育政策,并将其定为中国的基本 国策之一。40多年来, 以“一对夫妇只生育一个孩 子”为主要内容的计划生育政策使中国的人口形势 发生了巨大变化, 对于降低中国人口增长速度、控 制快速增长的人口规模产生了显著的作用(陶涛 等, 2011)。然而, 中国计划生育政策在“创造奇迹” 的同时, 国内外学者更多地关注计划生育政策实施 几十年后中国生育率将持续低迷、老龄化程度加 剧、出生性别比严重失衡、劳动年龄人口持续减少 等负面影响 (Ahn, 1994; Bogg, 1998; Settles et al, 2002; 郭志刚等, 2002; 叶华等, 2011), 并围绕现行 生育政策是否应该调整、何时调整以及如何调整等 问题进行了深人探讨 (陈友华, 2008; 王广州,
2015)。大部分学者基本认可了进一步调整生育政 策的必要性, 只是在调整路径与时间选择上存在一 定分歧(乔晓春等, 2006; 徐俊, 2014)。

在此背景下, 2013 年 11 月,党的十八届三中全 会提出: “坚持计划生育的基本国策,启动实施一方 是独生子女的夫妇可以生育两个孩子的政策”, 即 “单独二孩”政策。这也是 40 多年来中国计划生育 政策的首次重大调整。此政策一出,立即引起了全 社会的强烈反响, 并成为学术界关注的焦点。学者 们主要针对全国或特定地区育龄妇女生育意愿的 调查分析(庄亚儿等, 2014)、“单独二孩”放开后未来 人口数量变化的测算与分析(乔晓春, 2014a)以及可 能带来的社会影响(风笑天, 2014)等内容进行深人 研究。还有些学者主张并呼吁全面放开二孩,认为 “尽快实施城乡普遍允许二孩政策既利国又惠民” (曾毅, 2015), 并对放开二孩后的生育水平和人口变

收稿日期:2016-04; 修订日期: 2016-10。

基金项目: 国家自然科学基金项目 (41371178, 41471126) [Foundation: National Natural Science Foundation of China,

No.41371178, No.41471126]。

作者简介:王开泳(1980-),男,山东滕州人,博士,副研究员,研究方向为城市地理与政区地理,E-mail: wangky@igsnrr.ac.cn。 
化进行了测算, 对其可能带来的人口学后果(翟振 武等, 2014)展开了讨论。

2015 年 10 月底, 中共十八届五中全会决定: 坚 持计划生育的基本国策, 完善人口发展战略, 全面 实施“一对夫妇可生育两个孩子”政策。2015年底， 第十二届全国人大常委会第十八次会议审议通过 了人口与计划生育法修正案草案, 进一步明确了全 面二孩政策自 2016 年 1 月 1 日起施行。这是继 2013 年十八届三中全会决定启动实施“单独二孩” 政策之后的又一次人口政策调整, 必将对中国未来 的人口形势产生进一步的影响。由于中国不同地 区的人口基数不同, 生育水平和生育意愿也不相 同,因此这种影响必然具有区域差异性。然而从目 前的研究来看, 人口学者主要关注人口政策调整后 的生育行为、人口规模与结构以及人口学效应(马 力等, 2014; 翟振武等, 2014; 薛君, 2016), 较少关注 其区域差异及空间格局; 而地理学者虽擅长从地理 视角研究人口的空间分布、变动及增长的空间变化 (马颖忆等, 2012; 柏中强等, 2015; 刘涛等, 2015), 但 对于近年来人口生育政策调整后区域人口格局的 研究较少。为此,本文借助人口学的队列元素法, 一方面测算全面放开二孩后中国总人口及人口结 构的变化趋势, 另一方面从地理学的角度研究全面 放开二孩对中国区域人口空间格局的影响, 以期为 中国未来人口的空间变化以及相关区域政策设计 提供参考依据。

\section{2 数据与方法}

\section{1 数据来源}

本文的基础数据主要来源于 2010 年中国人口 普查资料、各省(市、自治区) 2010 年人口普查资料, 以及中国统计年鉴(2011-2015)和各省市自治区统 计年鉴(2011-2015), 所选数据的人口统计口径均为 常住人口。另外, 还参考了 2013 年 8 月中国人口与 发展研究中心在中国不包括西藏和新疆的 29 个省 (市、自治区)所作的 “全国生育意愿调查” 数据。这 项调查是由国家卫生计生委委托的, 旨在了解全国 及各地居民生育意愿的最新情况, 为调整完善生育 政策特别是放开 “单独二孩”政策做准备。该调查 以 20 44 周岁的男、女育龄人群为目标, 采用分层、 多阶段、与规模成比例的概率比例规模抽样(PPS 抽 样), 选择的样本量为 63600 人, 调查范围广, 调查结
果较为权威。

\section{2 人口预测方法原理}

目前, 已有较多的人口预测方法与模型, 主要 包括 Logistic 回归、Leslie 矩阵、灰色系统等数学模 型预测方法(陈楠等, 2006; 李永浮等, 2006; 任强 等, 2011; 张海峰等, 2013), 基于人口本身变动要素 和人口学原理的队列要素法(Billari et al, 2014; 苏 昌贵, 2014; Wilson, 2016), 以及通过人口增长与经 济发展进行关联的社会经济模型法(Ballard et al, 1980; Plaut, 1981)等, 每种方法都具有各自的优缺 点。其中, 队列要素法能结合人口变动因素和人口 队列数据进行队列年龄推移, 得到一个较为准确的 人口预测值(Stauffer, 2002), 因此得到学术界的普 遍认可(Lutz et al, 1997)。在一般统计中, 育龄妇女 的年龄一般为 15 49 岁,但由于 20 岁以下和 44 岁 以上的已婚妇女受生育政策调整的影响较小, 几乎 可忽略不计,并且全国生育意愿调查数据的目标人 群也是 20 44 岁人群, 故本文将育龄妇女定位于 20 44岁。本文借助队列要素法的思想对中国人口 进行预测, 并着重分析总人口与年龄结构的变化趋 势,算法原理如下(曾毅等, 2011; 王宏等, 2015):

首先, 计算初始预测分年龄人口的未来剩余情 况,公式为:

$$
\begin{gathered}
P_{x+1}^{t}=P_{x}^{t} \times\left(1-D_{x}\right) \\
P^{t}=\sum_{x=0}^{120} P_{x+1}^{t}
\end{gathered}
$$

式中: $P_{x+1}^{t}$ 为 $t$ 年 $x+1$ 岁的人口数; $P_{x}^{t}$ 为 $t$ 年 $x$ 岁的 人口数; $D_{x}$ 为从年龄 $x$ 岁到 $x+1$ 岁的死亡概率; $P^{t}$ 为各年龄组 $($ 除 0 岁组) 人口总数。

其次, 计算年度出生人数, 公式为:

$$
B^{t}=\sum_{x=20}^{44}\left(f_{x} \times W_{x}\right)
$$

式中: $B^{t}$ 为 $t$ 年出生人口数; $f_{x}$ 为分年龄生育率; $W_{x}$ 为分年龄育龄妇女数。

据此, 可进一步推导年度总和生育率(乔晓春, 2014b), 公式为:

$$
\begin{aligned}
& B^{t}=\sum_{x=20}^{44}\left(f_{x} \times W_{x}\right)=\sum_{x=20}^{44}\left(\beta \times h_{x} \times W_{x}\right)=\beta \times K \\
& \text { 这里, } \quad K=\sum_{x=20}^{44}\left(h_{x} \times W_{x}\right)
\end{aligned}
$$

式中: $\beta$ 为总和生育率; $h_{x}$ 为分年龄标准化生育 率; $K$ 为标准化生育人口总数, 可根据 2010 年人口 普查数据计算得出, 若假定 $K$ 值近年来保持不变, 
已知年度出生人数 $B^{t}$, 则可以得到总和生育率 $\beta$ 的估计值。

然后,计算出生人口的未来剩余情况：

$$
P_{0}^{t+1}=B^{t} \times\left(1-D_{0}\right)
$$

式中: $P_{0}^{t+1}$ 为 $t+1$ 年年初 0 岁组人口数; $D_{0}$ 为 $0 \sim 1$ 岁 的死亡概率。

最后, 计算 $t$ 年年末的人口数:

$$
P=P^{t}+P_{0}^{t+1}
$$

式中: $P$ 为 $t$ 年各年龄组人口总数。

在以上计算基础上,可根据 $t$ 年各年龄组的人 口总数计算老龄化系数、抚养比等指标的变化来定 量表达全面放开二孩对中国人口结构的影响。计 算公式为:

$$
\begin{gathered}
K_{\mathrm{o}}=P_{60^{+}} / P \\
R_{\mathrm{d}}=\left(P_{0 \sim 14}+P_{60^{+}}\right) / P_{15 \sim 59}
\end{gathered}
$$

式中: $K_{\mathrm{o}}$ 为老龄化系数; $R_{\mathrm{d}}$ 为抚养比; $P_{0 \sim 14}$ 为 $0 \sim 14$ 岁之间的人口; $P_{15 \sim 59}$ 为 15 59 岁之间的人口; $P_{60^{+}}$ 为 60 岁及以上的人口; $P$ 为总人口。

\section{3 区域人口空间格局分析方法}

首先, 对各省未来 15 年人口总量进行预测, 将 其分别除以省级行政区划面积即可得到分省的人 口密度,进而分析中国省际人口空间格局的变化。 省际人口总量为人口自然增长量和省际流动人口 量之和, 其中, 人口自然增长量根据队列要素法预 测, 省际流动人口量按照邓羽等(2014)的方法进行 预测。然后, 以分省未来 15 年人口密度变化标准差 作为省际人口变化强度判别指标, 可将中国划分为 人口快速变化区、人口中速变化区、人口低速变化 区和人口平稳区 4 类。最后, 对各种人口格局类型 区的特征和变化态势进行分析,计算公式为:

$$
\begin{gathered}
D P_{n}^{t}=T P_{n}^{t} / A_{n} \\
S D_{n}=\sqrt{\sum_{t=2016}^{2030}\left(D P_{n}^{t}-\overline{D P_{n}^{t}}\right)^{2} / 15}
\end{gathered}
$$

式中: $D P_{n}^{t}$ 为省份 $n$ 在 $t$ 年的人口密度; $T P_{n}^{t}$ 为省份 $n$ 在 $t$ 年的总人口; $A_{n}$ 为省份 $n$ 的行政区域面积; $\overline{D P_{n}^{t}}$ 为人口密度平均值; $S D_{n}$ 为人口密度标准差。

\section{3 全面放开二孩对中国总人口及人口 结构的影响}

\section{1 全面放开二孩后人口总量的预测步骤} 前文介绍了基于队列要素法通过年龄移算来
进行人口预测的基本原理,但在全面放开二孩的背 景下,预测未来人口还必须考虑更多的因素。全面 放开二孩意味着生育政策的调整。由于中国已推 行了 40 多年的计划生育政策,这期间积累了众多被 原生育政策限制但符合现在全面二孩政策条件的 潜在生育人群。政策调整后,这些潜在生育人群会 在之后的几年进行生育释放,从而使得政策调整后 的最初几年的生育数量和生育水平产生较大变 化。因此,生育释放期间的人口预测是重点, 并且 其预测方法也有所不同。总的来说, 包括以下几个 步骤:

\subsection{1 潜在生育人群的估计}

首先, 根据 2010 年全国人口普查资料, 通过队 列要素法估计 2015 年全国除新疆和西藏之外的 29 个省(市、自治区) 20 44 岁分年龄已婚育龄妇女人 数, 结果为 21149.35 万。

然后, 根据全国生育意愿调查数据, 可计算出 符合“全面二孩”政策的目标人群占所有已婚育龄 妇女总数的 $45.56 \%$ (详细计算过程见乔晓春 $(2014 \mathrm{~b}$ ) 的研究), 即 9636.08 万。其中, 有 $48.1 \%$ 的人表示 “要第 2 个孩子”, $13.6 \%$ 表示“说不好”(庄亚儿等, 2014)。若假定“全面二孩”目标人群的生育意愿与 此一致,那么如果把 “要第 2 个孩子” 的人群作为最 低估计(占比 $48.1 \%$ ), 而把“要第 2 个孩子”和“说不 好”之和作为最高估计(占比 $61.7 \%$ ), 则潜在生育人 群数量的最低估计为 4631.71 万, 最高估计为 5940.85 万。

最后, 考虑全国“单独二孩” 实施情况的影响。 由于从 2013 年 11 月 - 2015 年底实施了 2 年的“单独 二孩”政策,在此期间,“全面二孩”政策的潜在生育 人群会释放一部分。根据国家卫生和计划生育委 员会发布的《2015 年卫生和计划生育事业发展统计 公报》, 截至 2015 年 12 月底, 全国共约 200 万对独生 子女夫妇提出再生育申请(新华社, 2016)。由此可 以估计,经过“单独二孩”政策 2 年的释放,到 2015 年底, “全面二孩”的潜在生育人群数量最低估计约 为 4431 万, 最高估计约为 5740 万。

\subsection{2 新增出生人口及出生人口总数的测算}

由于全面放开二孩政策后, 所有的潜在生育人 群并不会选择在政策开放后的一年内集中生育,而 是在数年内逐步进行生育释放的。根据 2005 年全 国 $1 \%$ 人口抽样调查普查数据的计算结果, 可知中 国妇女生育一、二胎的平均间隔时间在 4 年左右, 那 
么可以假设全面开放二孩后累积的潜在生育能量 会在之后的 4 年内逐步释放, 并且释放的比例分别 为 $20 \% 、 35 \% 、 25 \%$ 和 $20 \%$ (乔晓春, $2014 b$; 翟振武 等, 2014)。那么, 就可以计算出 2016年全面放开二 孩后,未来 4 年每年新增出生人口数量的上限和下 限。根据中国统计年鉴近年来对中国总人口的统 计及变化趋势, 2011-2015 年, 每年出生人口数依次 为 1604 万、 1635 万、 1640 万、 1687 万、 1655 万, 因此, 假设未来 4 年每年全国正常出生人口为 1700 万, 再 加上每年新增的出生人口数量, 即可得到未来 4 年 每年实际出生人口总量的上限和下限。再根据每 年出生人口的总量及式(4)-(5), 进而可以估计出未 来 4 年的总和生育率。2016-2019年各年新增出生 人口、出生人口总数及总和生育率的估计值如表 1 所示。可以看出,2016年全面放开二孩后,生育释 放期间的出生人口数会有大幅提升, 在 2017 年峰值 时达到 3251.1 3709.3 万; 总和生育率较 2015 年的 1.66 左右也有大幅提升, 2016 年达到 2.57 2.84, 在 2017 年峰值时达到 3.24 3.69, 到 2019 年又回落到 2016 年的水平。

\subsection{3 未来 15 年总人口及年龄结构的预测}

由于全面放开二孩后, 历史上累积的潜在生育 量的释放会导致短暂的出生人口数量和总和生育 率波动, 之后会回落到一个稳定水平, 因此, 未来 15 年总人口的预测需分 2 个部分进行。

(1) 2016-2019 年生育释放期间的预测。该时 间段根据上一步骤估计出的每年出生人口总量, 再 通过队列元素法经年龄移算即可得到 2016-2019年 的总人口及年龄结构。
(2) 2019 年之后的预测。从 2020 年开始,由于 历史累积的生育能量已释放完, 全国妇女的生育水 平会稳定在某个水平。至于稳定在多少,有的学者 认为总和生育率会在 1.8 左右 (蔡昉, 2015), 也有的 学者认为会达到 2.0 2.1 左右 (乔晓春, 2014b), 尚未 得出统一的结论。本文根据全国生育意愿调查结 果, 以全国理想子女数 1.93 作为 2020 年及以后的总 和生育率。该结果是经全国范围内调查得出, 具有 一定的科学性和代表性。得到总和生育率的估计 结果后, 再根据队列元素法即可估计当年的出生人 口数, 进而估计出历年的总人口及年龄结构。另 外, 由于本文所用的方法较适合于短中期的预测, 进行长期的预测会有一定的误差, 因此预测的年限 至2030年末。

\section{2 全面放开二孩对中国总人口的影响}

表 2 为未来 15 年总人口的预测结果。由于符 合全面二孩政策的目标人群较多,历史累积的潜在 生育能量较大, 政策放开后, 会导致年度出生人口 和妇女时期生育水平的急剧增加和波动, 从而影响 中国未来 15 年的总人口规模。由表 2 可知, 从 2016 年全面放开二孩后, 中国总人口迅速增加, 到 2020 年, 总人口最低估计 14.558 亿, 最高估计 14.688 亿, 人口均值为 14.623 亿; 到 2030 年, 总人口最低估计 增加到 15.225 亿, 最高估计增至 15.355 亿, 人口均 值达到 15.29 亿。从人口的增长速度来看, 全面放 开二孩前, 2010-2015 年的人口年均增长率为 $6.1 \%$; 全面放开二孩后, 以人口估计均值为例, $2015-2020$ 年的人口年均增长率为 $12.5 \%, 2020$ 2025 年为 $5.2 \% 0,2025-2030$ 年为 $3.8 \% 0,2015-2030$ 年

表 $12016-2019$ 年新增出生人口、出生人口总量及总和生育率估计

Tab.1 Estimation of added newly-born population, total newly-born population, and total fertility rate, $2016-2019$

\begin{tabular}{|c|c|c|c|c|}
\hline 估计指标 & 2016年分布比例 20\% & 2017 年分布比例 $35 \%$ & 2018 年分布比例 $25 \%$ & 2019年分布比例 20\% \\
\hline \multicolumn{5}{|l|}{ 出生人口增量/万 } \\
\hline 下限 & 886.34 & 1551.10 & 1107.93 & 886.34 \\
\hline 上限 & 1148.17 & 2009.30 & 1435.21 & 1148.17 \\
\hline 均值 & 1017.26 & 1780.20 & 1271.57 & 1017.26 \\
\hline \multicolumn{5}{|l|}{ 出生人口总量/万 } \\
\hline 下限 & 2586.34 & 3251.10 & 2807.93 & 2586.34 \\
\hline 上限 & 2848.17 & 3709.30 & 3135.21 & 2848.17 \\
\hline 均值 & 2717.26 & 3480.20 & 2971.57 & 2717.26 \\
\hline \multicolumn{5}{|l|}{ 总和生育率 } \\
\hline 下限 & 2.57 & 3.24 & 2.79 & 2.57 \\
\hline 上限 & 2.84 & 3.69 & 3.12 & 2.84 \\
\hline 均值 & 2.71 & 3.46 & 2.96 & 2.71 \\
\hline
\end{tabular}


表 2 全面放开二孩后 15 年(2016-2030 年)中国

总人口预测结果

Tab.2 Estimation of total population in China after a transition to a universal two-child policy, 2016-2030

\begin{tabular}{cccc}
\hline \multirow{2}{*}{ 年份 } & \multicolumn{3}{c}{ 总人口/亿 } \\
\cline { 2 - 4 } & 下限 & 上限 & 均值 \\
\hline 2016 & 13.906 & 13.933 & 13.919 \\
2017 & 14.135 & 14.207 & 14.171 \\
2018 & 14.316 & 14.420 & 14.368 \\
2019 & 14.471 & 14.601 & 14.536 \\
2020 & 14.558 & 14.688 & 14.623 \\
2021 & 14.641 & 14.772 & 14.707 \\
2022 & 14.722 & 14.852 & 14.787 \\
2023 & 14.798 & 14.928 & 14.863 \\
2024 & 14.871 & 15.001 & 14.936 \\
2025 & 14.940 & 15.070 & 15.005 \\
2026 & 15.005 & 15.135 & 15.070 \\
2027 & 15.066 & 15.196 & 15.131 \\
2028 & 15.123 & 15.253 & 15.188 \\
2029 & 15.176 & 15.306 & 15.241 \\
2030 & 15.225 & 15.355 & 15.290 \\
\hline
\end{tabular}

为 $7.2 \%$ 。可以看出,全面放开二孩后,中国总人口 的增长速度呈现 “快升快降” 的增长规律, 并且放开 后的整体增长速度快于放开前的增长速度。

为进一步刻画全面放开二孩对中国总人口的 影响, 根据 2010 年全国人口普查资料及历年中国统 计年鉴的数据,通过队列要素法模拟了生育政策维 持不变情况下的人口未来走势, 并将其与全面放开 二孩条件下的人口未来走势(估计均值,下同)进行 对比(图 1)。由图 1可以看出,若维持独生子女生育 政策不变,到 2030 年中国总人口仍会持续增加,但 增加的速度和幅度都逐渐放缓, 2020 年将达到 14.093 亿, 到 2030 年将达到 14.523 亿。全面放开二 孩后, 可明显地改变中国未来人口的发展轨迹, 在 一定时期内提升人口增加的速度和幅度。到 2020 年, 总人口达到 14.623 亿, 比维持政策不变多出 5300 万; 到 2030 年, 总人口将达到 15.29 亿, 比维持 政策不变多出 7670 万,差异十分明显。再从 2030 年以后人口的走势来看, 若维持政策不变, 中国将 马上进人人口负增长时期,而全面放开二孩可以有 效地延缓中国总人口的递减趋势。但从另一个角 度来看,全面放开二孩后多出生的人口也将给中国 未来的资源环境产生更大的压力, 并对就业、基础 设施和公共服务设施等产生更大的需求,这些都应 该成为未来制定相关政策必须考虑的重要因素。

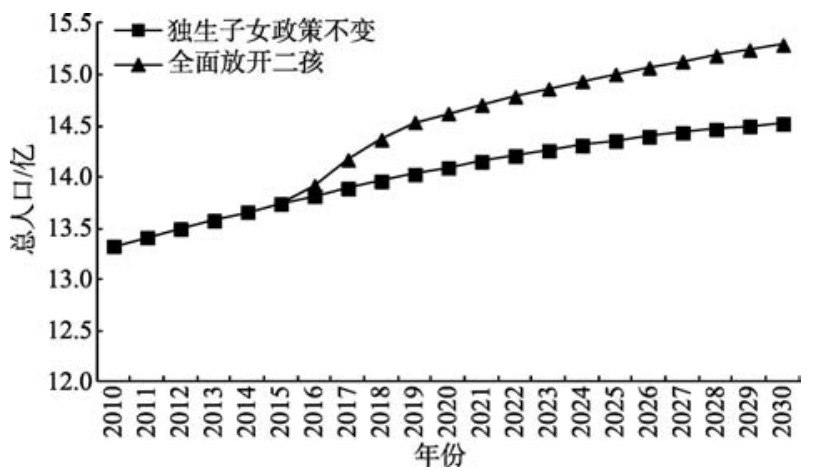

图 1 放开二孩政策前后(2010-2030年)中国 人口总量变化趋势对比

Fig.1 Projected population trends in China before and after the implementation of the universal two-child policy,

2010-2030

\section{3 全面放开二孩对中国人口结构的影响}

全面放开二孩不仅能改变中国未来总人口的 发展走势,而且也会对中国未来人口的年龄结构产 生较大影响(表 3)。为了进一步刻画全面放开二孩 对中国人口结构的影响,通过队列要素法模拟生育 政策维持不变情况下未来 15 年的人口结构,并将其 与全面放开二孩条件下未来 15 年的人口结构进行 对比(图 2)。

\subsection{1 对未来 15 年人口老龄化的影响}

2015 年, 全国 60 岁及以上老年人占总人口的 比重 (即老龄化系数)约为 $16.41 \%$ 。全面放开二孩 后,老龄化系数在 2020 年将达到 $17.85 \%$,在 2025 年 将达到 $20.82 \%$, 到 2030 年将达到 $24.25 \%$ 。可以看 出, 快速老龄化是中国今后要直面的人口问题之 一,全面放开二孩并不会直接影响中国未来一段时 间内老龄人口规模的变动, 未来 30 50年老龄化的 形势依然严峻。但是,若考虑生育政策不变的情 况, 2020 年全面放开二孩的老龄化系数比维持生育 政策不变的老龄化系数低 $0.67 \%, 2025$ 年和 2030 年 分别低 $0.94 \%$ 和 $1.28 \%$,并且随着时间的推移,两者 之间的差距也会逐渐拉大。这是由于全面放开二 孩增大了中国总人口的规模, 即增大了老龄化系数 的分母值, 从而延缓了老年人口比重的增长趋势。 由此可见,全面放开二孩可以有效地降低未来几十 年中国老龄化系数的上升速度, 延缓中国老龄化的 进程。

3.3.2 对未来 15 年及更长时期年劳动力供给的影响 生育政策的调整可对未来劳动力资源的供给 产生潜在的影响。由图 2 可以看出,2015-2030年期 
表 3 全面放开二孩后的 $2000 、 2025 、 2030$ 年中国人口结构预测结果

Tab.3 Demographic structures after a transition to a universal two-child policy in 2020, 2025 and 2030

\begin{tabular}{|c|c|c|c|c|c|c|}
\hline \multirow{2}{*}{ 年龄段/岁 } & \multicolumn{2}{|c|}{ 2020年 } & \multicolumn{2}{|c|}{ 2025年 } & \multicolumn{2}{|c|}{ 2030年 } \\
\hline & 人数/万 & 比例/\% & 人数/万 & 比例 $/ \%$ & 人数/万 & 比例 $/ \%$ \\
\hline $0 \sim 4$ & 13765.64 & 9.414 & 9660.62 & 6.438 & 9660.62 & 6.318 \\
\hline $5 \sim 9$ & 8195.40 & 5.605 & 13728.95 & 9.150 & 9632.22 & 6.300 \\
\hline $10 \sim 14$ & 7520.65 & 5.143 & 8183.45 & 5.454 & 13708.98 & 8.966 \\
\hline $15 \sim 19$ & 7066.46 & 4.832 & 7508.55 & 5.004 & 8170.32 & 5.343 \\
\hline $25 \sim 29$ & 9939.84 & 6.798 & 7442.09 & 4.960 & 7031.93 & 4.599 \\
\hline $30 \sim 34$ & 12663.87 & 8.660 & 9906.14 & 6.602 & 7416.91 & 4.851 \\
\hline $35 \sim 39$ & 10020.03 & 6.852 & 12604.89 & 8.401 & 9859.42 & 6.448 \\
\hline $40 \sim 44$ & 9601.92 & 6.566 & 9951.32 & 6.632 & 12519.25 & 8.188 \\
\hline $45 \sim 49$ & 11597.88 & 7.931 & 9501.36 & 6.332 & 9847.21 & 6.440 \\
\hline $50 \sim 54$ & 12146.92 & 8.307 & 11408.42 & 7.603 & 9347.00 & 6.113 \\
\hline $55 \sim 59$ & 10146.32 & 6.939 & 11854.88 & 7.901 & 11130.52 & 7.279 \\
\hline $60 \sim 64$ & 7384.40 & 5.050 & 9769.01 & 6.511 & 11405.11 & 7.459 \\
\hline $65 \sim 69$ & 7338.35 & 5.018 & 6915.43 & 4.609 & 9173.44 & 6.000 \\
\hline $70 \sim 74$ & 4929.23 & 3.371 & 6568.52 & 4.378 & 6169.42 & 4.035 \\
\hline $75 \sim 79$ & 3040.78 & 2.079 & 4082.54 & 2.721 & 5436.40 & 3.555 \\
\hline $80 \sim 84$ & 1963.15 & 1.343 & 2194.18 & 1.462 & 2955.39 & 1.933 \\
\hline $85 \sim 89$ & 1013.50 & 0.693 & 1149.45 & 0.766 & 1287.01 & 0.842 \\
\hline $90 \sim 94$ & 344.18 & 0.235 & 440.50 & 0.294 & 496.65 & 0.325 \\
\hline $95+$ & 88.43 & 0.061 & 125.10 & 0.083 & 161.73 & 0.106 \\
\hline
\end{tabular}



图 2 放开二孩政策后未来 15 年中国人口结构变化趋势

Fig.2 Demographic structures after the implementation of the universal two-child policyy in 2020, 2025, and 2030

间,无论是全面放开二孩还是维持生育政策不变, 中国 15 59 岁的劳动人口规模和比重均处于下降之 中, 劳动人口规模从 2015 年的 92029.55 万分别下降 至 2020 年的 90645.78 万、2025 年的 87228.85 万和 2030 年的 82814.82 万。虽然 2 种情况下的劳动人 口规模一样, 但全面放开二孩下劳动人口的比重均 比维持生育政策不变的比重低。而从抚养比来看 (图 3),2015-2030年期间, 无论是全面放开二孩还是 维持生育政策不变, 中国人口的总抚养比均处于上 升之中, 并且全面放开二孩下的抚养比均比维持生
育政策不变的高。当然,这 2 种现象并不会一直都 这样。从 2031 年开始,全面放开二孩的情况将得到 明显改善。因为在2016-2030 年期间,全面放开二 孩增加了少儿人口(0 14 岁)的比重, 从而使得短期 内劳动人口所占比重降低、社会抚养负担加重, 并 且这期间大规模新出生的人口尚未进人劳动年龄; 而从 2031 年开始, 当这些人口逐渐进人劳动力市场 后, 将明显增加未来劳动力的供给, 从而使得劳动 人口的规模和比重有所回升, 抚养比有所下降, 可 明显缓解中国劳动力资源短缺、社会抚养负担较重 
的局面。但是,若维持生育政策不变,2030年后中 国劳动人口的规模和比重仍将持续下降, 抚养比也 仍将持续上升。由此可见,全面放开二孩虽然会在 短期内(前 15 年)加重社会抚养负担, 但从长期来

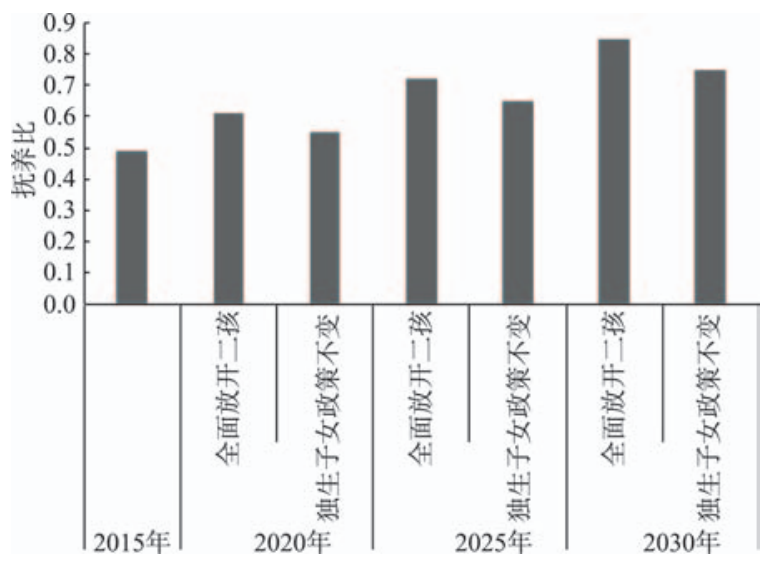

图 3 未来 15 年中国人口总抚养比变化趋势

Fig.3 Trend of total dependent rate after the implementation of the universal two-child policy in 2020, 2025, and 2030
看, 可以明显增加劳动力的供给,改变维持生育政 策不变情况下未来劳动人口不断走低的态势。

\section{4 全面放开二孩对区域人口空间格局 的影响}

\section{1 全面放开二孩后区域人口空间格局的变化}

省际人口变化由自然增长和迁移增长 2 个部分 构成。根据各省市区的 2010 年人口普查资料及全 国生育意愿调查相关数据, 按照前文全国人口的预 测步骤与方法进行测算, 全面放开二孩后的省际人 口自然增长的预测结果如图 4 所示。其中, 由于全 国生育意愿调查不涉及新疆和西藏, 因此这 2 个地 区按照一般的队列元素法进行预测。省际流动人 口的迁移增长按照邓羽等(2014)的方法进行预测, 结果如图 5 所示。从省际人口自然增长预测结果来 看, 全面放开二孩后, 各省的人口规模增长明显, 广 东、浙江、福建、江西、海南等省份2015-2030年间的

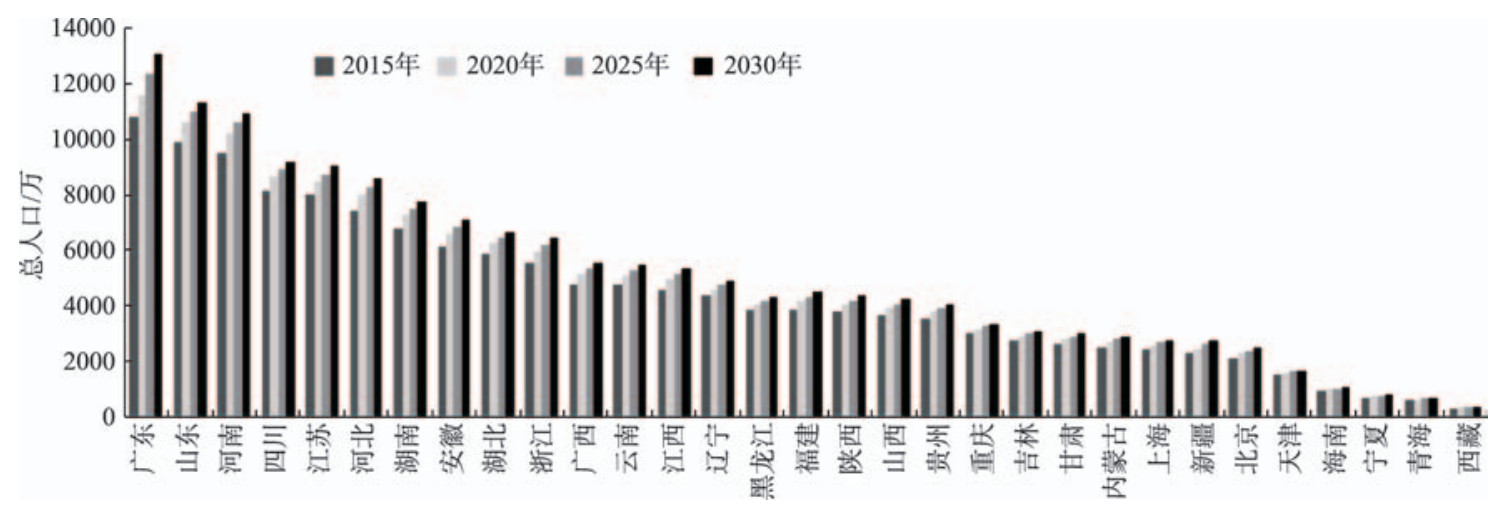

图 4 未来 15 年省际人口自然增长预测结果

Fig.4 Provincial natural population growth forecast after the implementation of the universal two-child policy in 2020, 2025, 2030

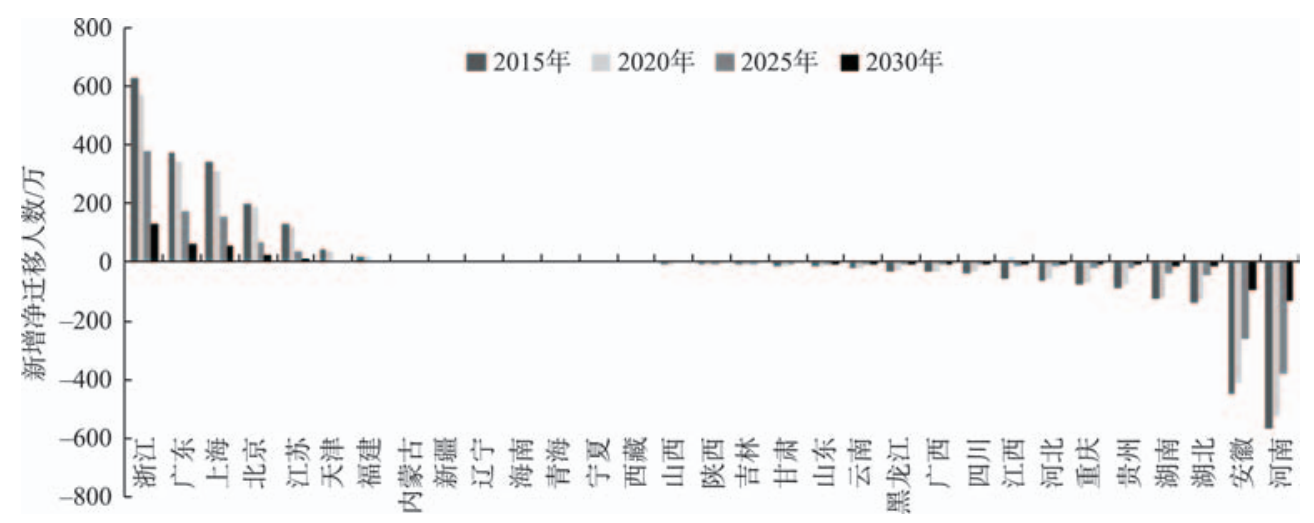

图 5 未来 15 年省际流动人口净迁移量预测结果

Fig.5 Provincial-level net migration of the floating population in 2020, 2025, and 2030 
人口年均增长率均超过了 $10 \%$, 其中, 广东的年均 增长率最高, 达到 $12.85 \%$ 。从省际流动人口净迁 移预测结果来看, 浙江、广东、上海、北京、江苏、天 津和福建等是中国主要的人口净迁人区域, 而河 南、安徽、湖北、湖南、贵州、重庆、河北等是中国主 要的人口净迁出区域。随着时间的推移, 各省的净 迁人或净迁出的人口逐渐减少且净迁移方向保持 一致, 到 2030 年, 省际人口流动接近平衡状态。

由省际人口自然增长量和净迁移量预测结果 可计算得到各省未来 15 年人口总量, 在此基础上分 别绘制全国各省市区全面放开二孩前的 2015 年以 及放开后的 2020、2025 和 2030 年几个时间节点的 人口密度图(图6), 以反映省际人口空间格局的演变 趋势。从各省未来 15 年的人口密度变化来看, 全面 放开二孩前后, 中国的区域人口空间格局均呈现东 部人口密度最高、中部次之、东北再次、西部最低的 总体格局。全面放开二孩后, 东部沿海地区的上 海、北京、天津、江苏 4 个省份的人口密度均保持在 前 4 位, 平均人口密度分别为 4457、1448、1362 和 840 人 $/ \mathrm{km}^{2}$ 。山东的人口密度在 2030 年前均保持在 全国第 5 位,但 2030 年开始被广东超越而降至第 6 位。海南是东部省份中位序最末的, 始终保持在 17
位, 人口密度均值为 282 人/km²。中部的河南在 2030 年前一直名列全国第 8 位, 到 2030 年超越浙江 上升至第 7 位, 人口密度均值为 597 人 $/ \mathrm{km}^{2}$; 同为中 部的人口大省安徽, 基本稳定在第 9 位, 人口密度均 值为 456 人 $/ \mathrm{km}^{2}$; 而湖南、湖北、江西和山西 4 省的 人口密度均在 250 350 人 $/ \mathrm{km}^{2}$ 之间。东北三省中只 有辽宁位居前 20 位, 其人口密度均值 317 人 $/ \mathrm{km}^{2}$, 始终名列第 15 位; 而吉林和黑龙江分别稳定在第 23 和 26 位左右, 人口密度均值分别为 156 人 $/ \mathrm{km}^{2}$ 和 89 人 $/ \mathrm{km}^{2}$ 。西部除重庆稳定在第 11 位外, 其余省区 的人口密度基本位居全国 20 名以后, 其中,甘肃、内 蒙古、新疆、青海和西藏均名列全国最末 5 位, 平均 人口密度分别为 $62 、 23 、 15 、 9$ 和 3 人 $/ \mathrm{km}^{2}$ 。总体来 看, 中国人口密度的区域空间格局基本上较为稳 定,东南集聚西北相对稀疏的分布格局将会长期 存在。

从省际人口密度的变化区域来看, 全面放开二 孩将对胡焕庸线两侧的人口格局产生一定的影 响。由图6 可直观看出, 全面放开二孩后,胡焕庸线 东南侧的人口密度不断加大, 而西北侧的人口密度 无明显变化。这是由于中国原来的计划生育政策 本身就具有区域差异性,西部地区的很多少数民族
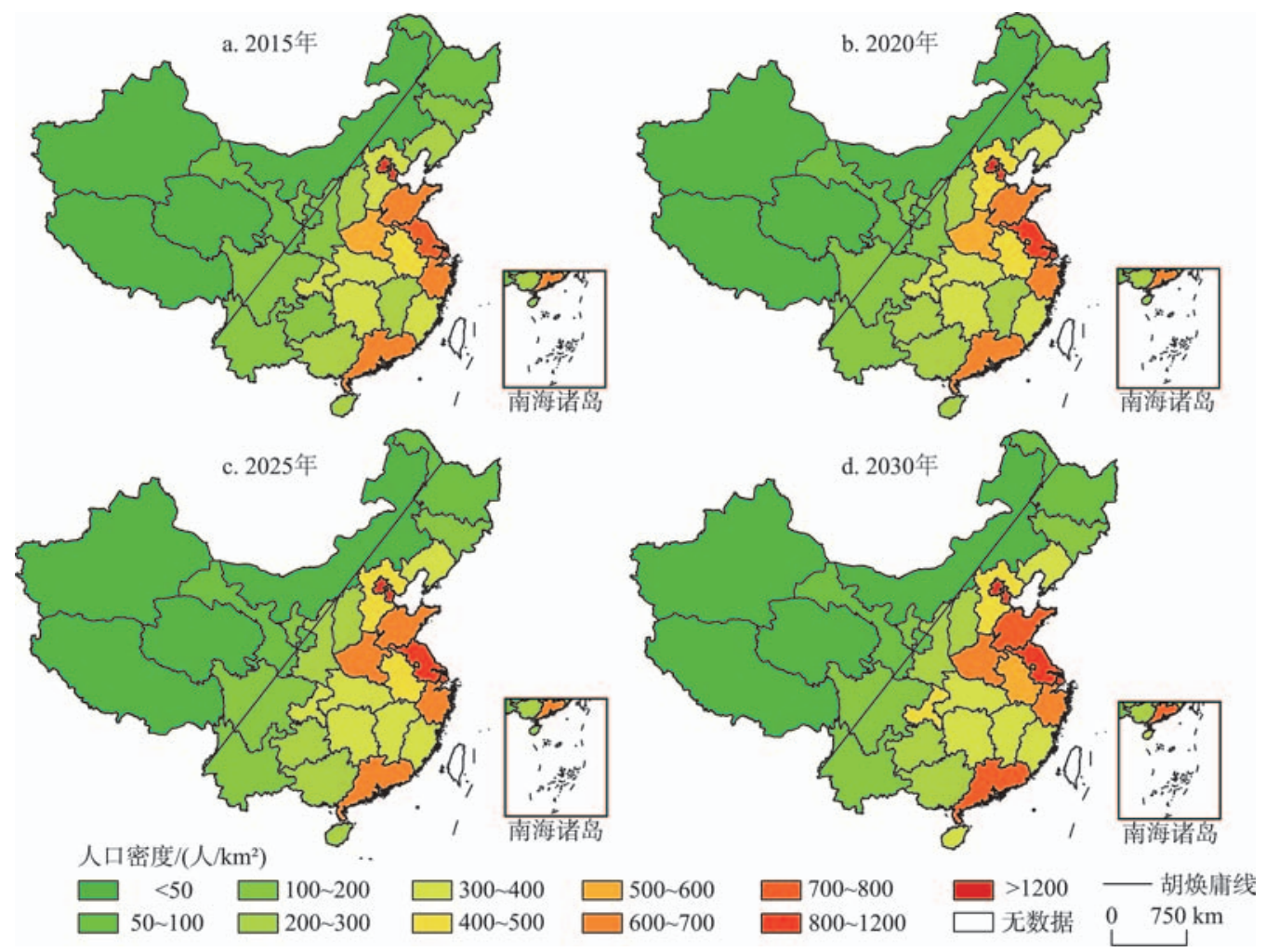

图6 2015、2020、2025、2030年中国区域人口空间格局演化

Fig.6 Population spatial distribution pattern in China in 2015, 2020, 2025, and 2030 
地区和农村地区原本就可以生育二孩甚至多孩,整 体受计划生育政策的限制比东部和中部地区要小 得多,历史累积的潜在生育量也比东部和中部地区 小。全面放开二孩后, 全国的生育政策趋于均等, 西部地区主要对城市产生一定的影响, 而东部和中 部地区则对城市和农村产生全方位的影响, 再加上 省际人口流动的区域主要也集中于东、中部地区, 因此胡焕庸线东南侧的人口比重将会进一步上升, 而西北侧的人口比重将会相对下降。

\section{2 省际人口空间格局变化类型与特征}

以全面放开二孩后分省(市、自治区)未来 15 年 人口密度变化标准差 $\left(S D_{n}\right)$ 作为人口变化强度的判 别指标, 利用 ArcGIS 10.0 的自然断点法, 可将中国 划分为人口快速变化区、人口中速变化区、人口低 速变化区和人口平稳区 4 类地区 (表 4、图 7)。人口 快速增长区包括上海、河南、广东、安徽、北京、山 东、天津、江苏和河北 9 个省级行政区,这些省市均 位于胡焕庸线东南侧, 大多是经济发达省市, 且人 口变化速度较快, 人口密度均值也都位居前 10 位。 其中, 上海的人口密度变化最大, 从 2015 年的 4378 人 $/ \mathrm{km}^{2}$ 增长到 2030 年的 4453 人 $/ \mathrm{km}^{2}$ 。同时, 在人口
快速变化区的省份中, 河南和安徽是流动人口净流 出最多的 2 个省份,2015-2030年间新增累计净迁移 人口规模超过了自然增长的人口规模; 上海、北京、 广东、江苏和天津是主要的人口净流人省份, 其中, 上海和北京的新增累计净迁移人口也超过了自然 增长的人口规模。人口中速变化区包括浙江、福 建、湖南、湖北、重庆、江西、海南和山西 8 个省级行 政区,这些省市的人口变化速度一般,并且也都位 于胡焕庸线东南侧。其中, 浙江流动人口净流人最 多,2015-2030年间, 其新增累计净迁人人口规模达 1714 万, 超过自然增长人口规模 $(917$ 万)。人口低 速变化区包括辽宁、广西、贵州、陕西、四川、云南、 宁夏和吉林 8 个省级行政区,这些省区的人口变化 速度不快, 除辽宁和吉林位于东北地区外, 其余省 份均属于西部地区, 并且在胡焕庸线两侧均有分 布。人口平稳区包括黑龙江、甘肃、内蒙古、新疆、 青海和西藏 6 个省级行政区, 这些省区的人口密度 变化不大,除黑龙江部分地区外基本位于胡焕庸线 西北侧。

从省际人口空间格局变化的类型划分及其人 口密度特征可以看出, 全面放开二孩对于胡焕庸线

表 4 2016-2030 年省际人口空间格局变化类型划分

Tab.4 Type of change of provincial-level population spatial distribution pattern, 2016-2030

\begin{tabular}{ccl}
\hline 人口空间格局变化类型 & 划分标准 $/\left(\right.$ 人 $\left./ \mathrm{km}^{2}\right)$ & \multicolumn{1}{c}{ 省级行政区 } \\
\hline 人口快速变化区 & $S D_{n}>25$ & 上海、河南、广东、安徽、北京、山东、天津、江苏、河北 \\
人口中速变化区 & $15<S D_{n}<25$ & 浙江、福建、湖南、湖北、重庆、江西、海南、山西 \\
人口低速变化区 & $5<S D_{n}<15$ & 辽宁、广西、贵州、陕西、四川、云南、宁夏、吉林 \\
人口平稳区 & $0<S D_{n}<5$ & 黑龙江、甘肃、内蒙古、新疆、青海、西藏 \\
\hline
\end{tabular}

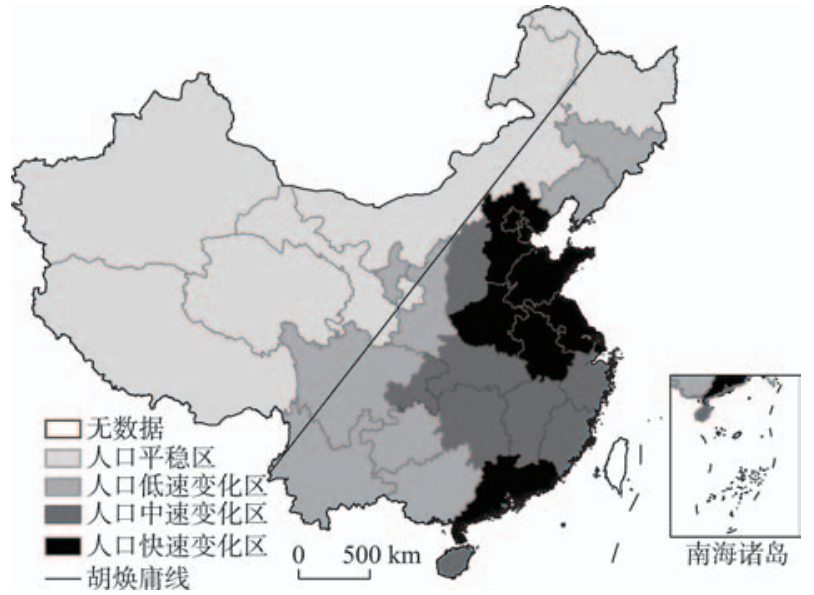

图 7 2016-2030年省际人口空间格局变化类型

Fig.7 Type of change of provincial-level population spatial distribution pattern in China, 2016-2030
东南侧尤其是东部沿海地区的人口影响远大于其 西北侧,并且东南集聚而西北稀疏的人口空间格局 将进一步加剧。由于东部地区的人地关系矛盾和 资源环境问题本身就较为突出, 全面放开二孩带来 的进一步人口集聚, 将给其带来更大的压力和挑 战。因此,各省市应根据相应的人口变化类型和趋 势, 提前制定合理的区域政策, 减轻全面放开二孩 带来的副作用,实现区域可持续发展。

\section{5 结论与讨论}

\section{1 结论}

本文借助人口学的队列元素法, 通过对符合全 面二孩政策的潜在生育人群和新增出生人口进行 
估计, 预测了全面放开二孩后中国总人口及人口结 构的变化趋势, 并从地理学的角度研究了全面放开 二孩政策对中国未来 15 年区域人口空间格局的影 响。主要结论如下:

(1) 全面放开二孩政策将对未来 15 年人口结构 和人口区域分布格局产生深远影响, 可明显地改变 中国人口的发展轨迹, 有效延缓中国总人口的递减 趋势, 并降低中国未来 15 年老龄化系数的上升速 度, 从而延缓中国老龄化的进程; 全面放开二孩政 策在短期内 (前 15 年)会加重社会抚养负担, 但从长 期来看, 可明显增加劳动力的供给, 改变维持生育 政策不变情况下劳动人口不断走低的态势。

(2) 全面放开二孩前后, 中国的区域人口空间 格局均呈现东部人口密度最高、中部次之、东北再 次、西部最低的总格局。总体来看, 中国人口密度 的区域空间格局基本上较为稳定, 东南集聚、西北 相对稀疏的空间格局将会长期存在并进一步加 剧。全面放开二孩还将影响胡焕庸线两侧的人口 格局, 其东南侧的人口密度不断加大, 而西北侧则 无明显变化。

(3) 根据各省全面放开二孩政策后未来 15 年人 口变化强度, 可将全国划分为人口快速变化区、人 口中速变化区、人口低速变化区和人口平稳区。各 省(市、自治区)应把握人口发展态势, 制定合理的人 口调控和区域应对政策, 有效提供公共服务和资源 配置, 实现人口与资源环境的可持续发展。

\section{2 讨论}

全面放开二孩是中国近年来人口政策的重大 调整, 将在一定程度上影响省际人口空间格局。然 而, 胡焕庸线所揭示的人口东密西疏格局仍不会发 生根本性变化, 并且这种基本地理格局将被进一步 强化。除此之外, 近年来, 随着西部大开发的持续 推进, 国家新型城镇化规划提出引导约 1 亿人在中 西部地区就近城镇化, “一带一路”和长江经济带打 造向西开放新格局,这些国家重大战略和政策的实 施, 都将对胡焕庸线两侧的人口格局产生一定的影 响,但总体上仍不会改变中国人口分布的基本空间 格局, 虽然具体的影响强度有待进一步研究。众多 研究表明, 胡焕庸线不仅是一条人口地理界线, 而 且也是一条自然和生态环境的综合界线, 其形成是 自然环境和人类活动长期作用的结果, 具有“不破” 特性(陈明星等, 2016; 王开泳等, 2016)。但是, 在遵 循胡焕庸线客观规律的基础上, 通过合理的人口、 产业布局和城镇空间组织, 胡焕庸线西北侧也能实
现经济更快发展和更高水平与质量的城镇化, 从而 缩短与东南侧的区域差距。

当然, 人口生育政策变动必然带来人口总量、 结构和空间布局的变化。由于生育政策调整带来 的影响往往具有滞后性,在政策调整和实施之初表 现不明显,但为减轻政策调整带来的长期副作用, 有必要对其潜在的社会影响进行前瞻性的预测和 研究。虽然全面放开二孩具有较多的禆益, 可以延 缓中国人口递减和老龄化的趋势并增加劳动力的 供给,但也必须估计到,全面放开二孩政策后一段 时期内的生育高峰会对幼儿园、儿童医疗机构等方 面产生巨大需求, 几年后对中小学数量和规模需求 产生进一步的连锁反应, 以及再往后有可能产生新 的高等教育难、就业难等问题; 同时,在微观层面也 会对生育家庭的人口结构、生活方式、社会抚养负 担以及养老保障等产生深刻影响和冲击; 另外,全 面放开二孩政策还会对不同地区的资源供给、公共 服务设施配置和环境保护等区域政策产生不同的 影响。这些问题都应该提前研究,防患于未然。

\section{参考文献(References)}

柏中强, 王卷乐, 杨雅萍, 等. 2015. 基于乡镇尺度的中国 25 省区人口分布特征及影响因素[J]. 地理学报, 70(8): 1229- 1242. [Bai Z Q, Wang J L, Yang Y P, et al. 2015. Characterizing spatial patterns of population distribution at township level across the 25 provinces in China[J]. Acta Geographica Sinica, 70(8): 1229-1242.]

蔡昉. 2015. 促进人口均衡发展 [N]. 经济日报, 2015-11-12

(03). [Cai F. 2015. Cujin renkou junheng fazhan[N]. Economic Daily, 2015-11-12(03).]

陈明星, 李扬, 龚颖华, 等. 2016. 胡焕庸线两侧的人口分布 与城镇化格局趋势: 尝试回答李克强总理之问 [J]. 地理 学报, 71(2): 179-193. [Chen M X, Li Y, Gong Y H, et al. 2016. The population distribution and trend of urbanization pattern on two sides of Hu Huanyong population line: A tentative response to Premier Li Keqiang[J]. Acta Geographica Sinica, 71(2): 179-193.]

陈楠, 林宗坚, 王钦敏, 等. 2006. 基于灰色理论的中国人口 空间分布模式预测 [J]. 经济地理, 26(5): 759-762. [Chen $\mathrm{N}$, Lin Z J, Wang Q M, et al. 2006. The forecast on the population spatial distribution pattern based on the gray theory[J]. Economic Geography, 26(5): 759-762.]

陈友华. 2008. 关于生育政策调整的若干问题 $[\mathrm{J}]$. 人口与发 展, 14(1): 24-35. [Chen Y H. 2008. Several problems on adjustment of fertility policy[J]. Population \& Development, 14(1): 24-35.]

邓羽, 刘盛和, 蔡建明, 等. 2014. 中国省际人口空间格局演 
化的分析方法与实证 [J]. 地理学报, 69(10): 1473-1486. [Deng Y, Liu S H, Cai J M, et al. 2014. Spatial pattern and its evolution of Chinese provincial population and empirical study[J]. Acta Geographica Sinica, 69(10): 1473-1486.]

风笑天. 2014. “单独二孩”: 生育政策调整的社会影响前瞻 [J]. 国家行政学院学报, (5): 57-62. [Feng X T. 2014. "Dandu erhai": Shengyu zhengce tiaozheng de shehui yingxiang qianzhan[J]. Journal of Chinese Academy of Governance, (5): 57-62.]

郭志刚, 刘金塘, 宋健. 2002. 现行生育政策与未来家庭结构 [J]. 中国人口科学, (1): 1-11. [Guo Z G, Liu J T, Song J. 2002. Present population policy and the future family structure[J]. Chinese Journal of Population Science, (1): 1-11.]

李永浮, 鲁奇, 周成虎. 2006. 2010 年北京市流动人口预测 [J]. 地理研究, 25(1): 131-140. [Li Y F, Lu Q, Zhou C H. 2006. The prediction of Beijing floating population in 2010 [J]. Geographical Research, 25(1): 131-140.]

刘涛, 齐元静, 曹广忠. 2015. 中国流动人口空间格局演变机 制及城镇化效应: 基于 2000 和 2010 年人口普查分县数 据的分析 [J]. 地理学报, 70(4): 567-581. [Liu T, Qi Y J, Cao G Z. 2015. China's floating population in the 21 st century: Uneven landscape, influencing factors, and effects on urbanization[J]. Acta Geographica Sinica, 70(4): 567-581.]

马力, 桂江丰. 2014. 中国完善生育政策战略研究: 基于 “十 二五” 期间放开“单独”的思考 [J]. 人口与发展, 20(2): 5366. [Ma L, Gui J F. 2014. Strategic research on improving the family planning policy of China: Based on the thinking of implement the policy of "2-child policy for only-child parent"[J]. Population \& Development, 20(2): 53-66.]

马颖忆, 陆玉麒, 张莉. 2012. 江苏省人口空间格局演化特征 [J]. 地理科学进展, 31(2): 167-175. [Ma Y Y, Lu Y Q, Zhang L. 2012. Evolvement of spatial pattern of population with data at county level in Jiangsu Province[J]. Progress in Geography, 31(2): 167-175.]

乔晓春. 2014a. “单独二孩”政策下新增人口测算方法及监测 系统构建 [J]. 人口与发展, 20(1): 2-12. [Qiao X C. 2014a. Methods of estimation on new born baby and construction of monitoring system under the new fertility policy[J]. Population \& Development, 20(1): 2-12.]

乔晓春. 2014b. 实施“普遍二孩”政策后生育水平会达到多 高: 兼与翟振武教授商榷 [J]. 人口与发展, 20(6): 2-15. [Qiao X C. 2014b. How high would be the fertility level if implementing "two- child policy": Discussion with Prof. Zhai Zhen-wu[J]. Population \& Development, 20(6): 2-15.] 乔晓春, 任强. 2006. 中国未来生育政策的选择 $[\mathrm{J}]$. 市场与人 口分析, 12(3): 1-13, 66. [Qiao X C, Ren Q. 2006. The choices of Chinese fertility policy in the future[J]. Market \& Demographic Analysis, 12(3): 1-13, 66.]

任强, 候大道. 2011. 人口预测的随机方法: 基于 Leslie矩阵 和 ARMA 模型[J]. 人口研究, 35(2): 28-42. [Ren Q, Hou D D. 2011. Stochastic model for population forecast: Based on Leslie matrix and ARMA model[J]. Population Research, 35(2): 28-42.]
苏昌贵. 2014. 湖南省未来人口预测与发展趋势分析 [J]. 经 济地理, 34(7): 20-27. [Su C G. 2014. The future population forecasting in Hunan Province and the development trend analysis[J]. Economic Geography, 34(7): 20-27.]

陶涛, 杨凡. 2011. 计划生育政策的人口效应 [J]. 人口研究, 35(1): 103-112. [Tao T, Yang F. 2011. The impact of China's family planning policy on demographic transition[J]. Population Research, 35(1): 103-112.]

王广州. 2015. 生育政策调整研究中存在的问题与反思 $[\mathrm{J}]$. 中国人口科学, (2): 2-15. [Wang G Z. 2015. Rethinking the problems in the research of China's family planning policy adjustment[J]. Chinese Journal of Population Science, (2): 2-15.]

王宏, 马香婷. 2015. 基于队列组元法的人口预测 [J]. 河北联 合大学学报: 社会科学版, 15(1): 13-17. [Wang H, Ma X T. 2015. Research on population prediction based on queue group element method[J]. Journal of Hebei United University: Social Science Edition, 15(1): 13-17.]

王开泳, 邓羽. 2016. 新型城镇化能否突破“胡焕庸线”: 兼论 “胡焕庸线”的地理学内涵 [J]. 地理研究, 35(5): 825-835. [Wang K Y, Deng Y. 2016. Can new urbanization break through the Hu Huanyong Line? Further discussion on the geographical connotations of the $\mathrm{Hu}$ Huanyong Line[J]. Geographical Research, 35(5): 825-835.]

新华社. 2016. 全国已有约 200 万对单独夫妇提出再生育申 请[EB/OL]. 新华网, 2016-07-21[2016-10-02]. http://news. xinhuanet.com/politics/2016- 07/21/c_1119259658.htm. [Xinhua News Agency. 2016. Quanguo yiyou yue 200 wandui dandu fufu tichu zai shengyu shenqing[EB/OL]. Xinhuanet, 2016- 07-21[2016- 10- 02]. http://news.xinhuanet. com/politics/2016-07/21/c_1119259658.htm.]

徐俊. 2014. 我国计划生育政策的反思与展望: 由“单独二 孩”引发的思考 [J]. 人口与经济, (6): 109-118. [Xu J. 2014. Reflection and prospect of China's birth controlling policy: Thinking from "couples to have a second baby if either is an only child"[J]. Population \& Economics, (6): 109-118.]

薛君. 2016. 用孩次递进比模拟“全面二孩”政策调整初期的 生育行为: 以湖北省为例 $[\mathrm{J}]$. 人口与经济, (3): 30-42. [Xue J. 2016. Use parity progression ratio method to predict fertility behavior under the universal two-child policy: Based on the data from Hubei Province[J]. Population \& Economics, (3): 30-42.]

叶华, 吴晓刚. 2011. 生育率下降与中国男女教育的平等化 趋势 [J]. 社会学研究, (5): 153-177. [Ye H, Wu X G. 2011. Fertility decline and the trend in educational gender inequality in China[J]. Sociological Studies, (5): 153-177.]

曾毅. 2015. 尽快实施城乡“普遍允许二孩”政策既利国又惠 民 [J]. 人口与经济, (5): 115-126. [Zeng Y. 2015. Implementing the universal two-child policy as soon as possible is a win-win policy for both the nation and people[J]. Population \& Economics, (5): 115-126.]

曾毅, 张震, 顾大男, 等. 2011. 人口分析方法与应用 $[\mathrm{M}] .2$ 
版. 北京: 北京大学出版社. [Zeng Y, Zhang Z, Gu D N, et al. 2011. Demographic analysis methods and applications [M]. 2nd ed. Beijing, China: Peking University Press.] 翟振武, 张现苓, 靳永爱. 2014. 立即全面放开二胎政策的人 口学后果分析 [J]. 人口研究, 38(2): 3- 17. [Zhai Z W, Zhang X L, Jin Y A. 2014. Demographic consequences of an immediate transition to a universal two-child policy[J]. Population Research, 38(2): 3-17.]

张海峰, 杨萍, 李春花, 等. 2013. 基于多模型的西宁市人口 规模预测 [J]. 干旱区地理, 36(5): 955-962. [Zhang H F, Yang P, Li C H, et al. 2013. Population prediction of Xining City based on multi-models[J]. Arid Land Geography, 36(5): 955-962.]

庄亚儿, 姜玉, 王志理, 等. 2014. 当前我国城乡居民的生育 意愿: 基于 2013 年全国生育意愿调查 $[\mathrm{J}]$. 人口研究, 38 (3): 3- 13. [Zhuang Y E, Jiang Y, Wang Z L, et al. 2014. Fertility intention of rural and urban residents in China: Results from the 2013 national fertility intention survey[J]. Population Research, 38(3): 3-13.]

Ahn N. 1994. Effects of the one-child family policy on second and third births in Hebei, Shaanxi and Shanghai[J]. Journal of Population Economics, 7(1): 63-78.

Ballard K P, Wendling R M. 1980. The national-regional impact evaluation system: A spatial model of U.S. economic and demographic activity[J]. Journal of Regional Science, 20(2): 143-158.

Billari F C, Graziani R, Melilli E. 2014. Stochastic population forecasting based on combinations of expert evaluations within the Bayesian paradigm[J]. Demography, 51(5): 1933-1954.

Bogg L. 1998. Family planning in China: Out of control[J]. American Journal of Public Health, 88(4): 649-651.

Lutz W, Sanderson W, Scherbov S. 1997. Doubling of world population unlikely[J]. Nature, 387: 803-805.

Plaut T R. 1981. An econometric model for forecasting regional population growth[J]. International Regional Science Review, 6(1): 53-70.

Settles B H, Sheng X W, Zang Y, et al. 2013. The one-child policy and its impact on Chinese families[M]//Kwok-bun C. International handbook of Chinese families. New York: Springer.

Stauffer D. 2002. Simple tools for forecasts of population ageing in developed countries based on extrapolations of human mortality, fertility and migration[J]. Experimental Gerontology, 37(8-9): 1131-1136.

Wilson T. 2016. Evaluation of alternative cohort- component models for local area population forecasts[J]. Population Research and Policy Review, 35(2): 241-261.

\title{
Influence of the implementation of the universal two-child policy on demographic structure and population spatial distribution in China
}

\author{
WANG Kaiyong ${ }^{1,2}$, DING Jun ${ }^{1,2,3}$, WANG Fuyuan ${ }^{1,2,3}$ \\ (1. Institute of Geographic Sciences and Natural Resources Research, CAS, Beijing 100101, China; \\ 2. Key Laboratory of Regional Sustainable Development Modeling, CAS, Beijing 100101, China; \\ 3. University of Chinese Academy of Sciences, Beijing 100049, China)
}

\begin{abstract}
From the policy allowing couples to have a second child if one parent is an only child to universal twochild policy, fertility policy in China had changed in succession, which had caused extensive social concerns and would have an influence on Chinese demographics in the future. This article projects the trend of total population and demographic structure in China after implementing the universal two-child policy by queue group element method from the demographic perspective, and analyzes the influence of the policy on Chinese population spatial distribution from a geographic perspective. The results show that: (1) Implementing a universal two-child policy can reduce the declining trend of the total population, aging of the population, and dropping of working age population. (2) Eastern China has the highest population density, followed by the central, northeastern, and western regions. Implementing a universal two-child policy can increase the population density of the area to the southeast of the $\mathrm{Hu}$ Line, but there will be little change to the northwest of the Hu Line. The current population spatial distribution pattern will continue to exist. (3) Based on the provincial-level annual change intensities of population density, China can be divided into rapid population growth zone, medium-speed population growth zone, slow population growth zone, and stable population zone.
\end{abstract}

Key words: universal two-child policy; demographic structure; spatial pattern; influence; China 